\title{
Correction to: Effect of nutritional and physical exercise intervention on hospital readmission for patients aged 65 or older: a systematic review and meta-analysis of randomized controlled trials
}

\author{
Ellisiv Lærum-Onsager ${ }^{1 * \dagger}$, Marianne Molin ${ }^{2,3 \dagger}$, Cecilie Fromholt Olsen ${ }^{4}$, Asta Bye ${ }^{2,5}$, Jonas Debesay ${ }^{2}$,
} Christine Hillestad Hestevik ${ }^{4,6}$, Maria Bjerk ${ }^{4,6}$ and Are Hugo Pripp ${ }^{7,8}$

Correction to: Int J Behav Nutr Phys Act 18, 62 (2021) https://doi.org/10.1186/s12966-021-01123-w

Following the publication of the original article [1], the authors identified an error in Fig. 2. The correct figure is given below.

The original article [1] has been corrected.

\section{Author details}

'Lovisenberg Diaconal University College, Oslo, Norway. ${ }^{2}$ Department of Nursing and Health Promotion, Faculty of Health Sciences, Oslo Metropolitan University, Oslo, Norway. ${ }^{3}$ Department of Health, Bjorknes University College, Oslo, Norway. ${ }^{4}$ Department of Physiotherapy, Faculty of Health Sciences, Oslo Metropolitan University, Oslo, Norway. ${ }^{5}$ Regional Advisory Unit for Palliative Care, Department of Oncology, Oslo University Hospital, Oslo, Norway. ${ }^{6}$ Norwegian Institute of Public Health, Oslo, Norway. ${ }^{7}$ Faculty of Health Sciences, Oslo Metropolitan University, Oslo, Norway. ${ }^{8}$ Oslo Centre of Biostatistics and Epidemiology, Research Support Services, Oslo University Hospital, Oslo, Norway.

Published online: 25 June 2021

\section{Reference}

1. Lærum-Onsager, et al. Effect of nutritional and physical exercise intervention on hospital readmission for patients aged 65 or older: a systematic review and meta-analysis of randomized controlled trials. Int J Behav Nutr Phys Act. 2021;18:62. https://doi.org/10.1186/s12966-021-01123-w.

The original article can be found online at https://doi.org/10.1186/s12966021-01123-w.

* Correspondence: ellisiv.onsager@ldh.no

${ }^{\dagger}$ Ellisiv Lærum-Onsager and Marianne Molin contributed equally to this work. 'Lovisenberg Diaconal University College, Oslo, Norway

Full list of author information is available at the end of the article

(c) The Author(s). 2021 Open Access This article is licensed under a Creative Commons Attribution 4.0 International License, which permits use, sharing, adaptation, distribution and reproduction in any medium or format, as long as you give appropriate credit to the original author(s) and the source, provide a link to the Creative Commons licence, and indicate if changes were made. The images or other third party material in this article are included in the article's Creative Commons licence, unless indicated otherwise in a credit line to the material. If material is not included in the article's Creative Commons licence and your intended use is not permitted by statutory regulation or exceeds the permitted use, you will need to obtain permission directly from the copyright holder. To view a copy of this licence, visit http://creativecommons.org/licenses/by/4.0/ The Creative Commons Public Domain Dedication waiver (http://creativecommons.org/publicdomain/zero/1.0/) applies to the data made available in this article, unless otherwise stated in a credit line to the data. 


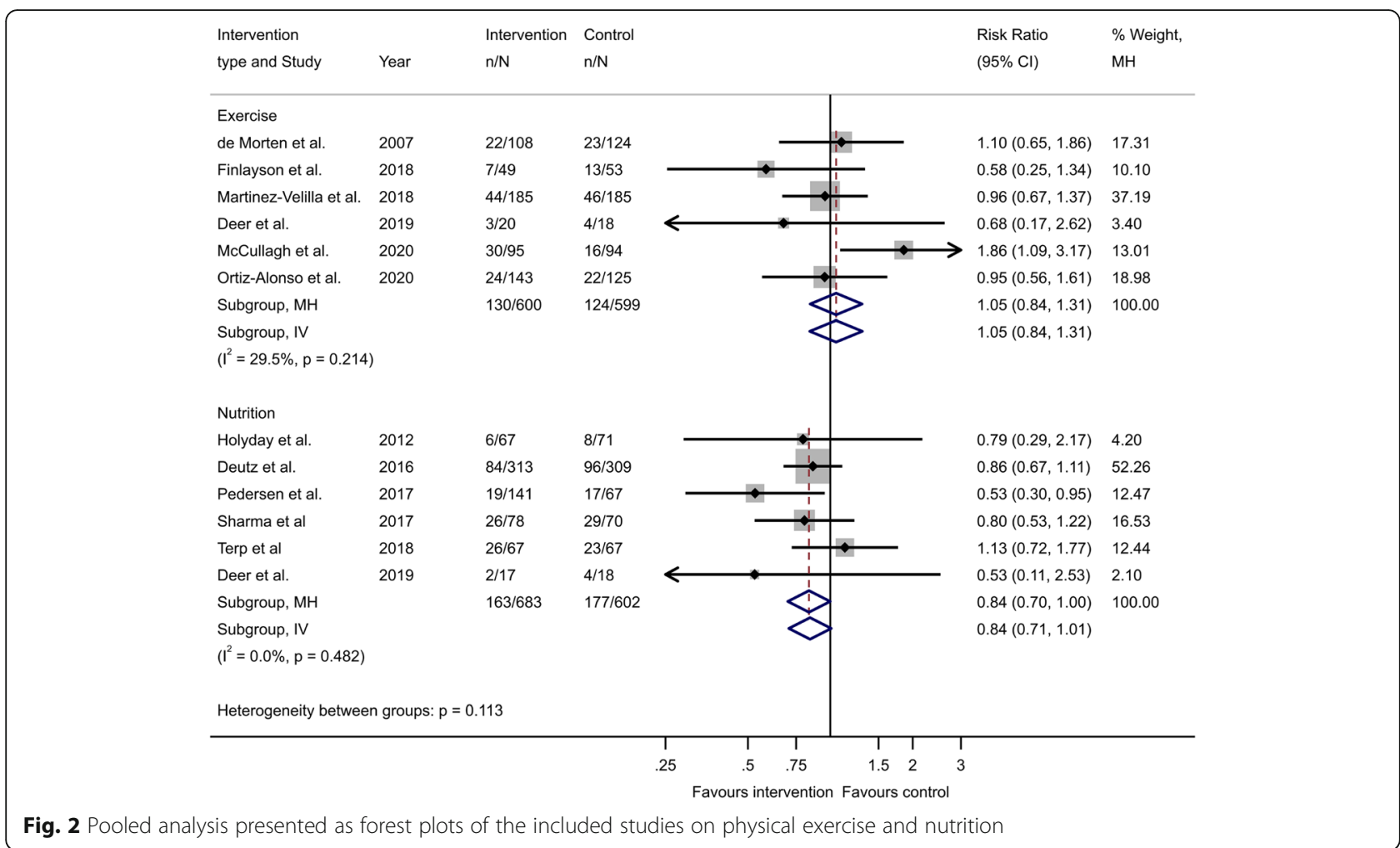

